\title{
STUDYING THE EFFECT OF LINEAR REFRACTION ON LOW-FREQUENCY WAVE PROPAGATION (PHYSICAL AND NUMERICAL STUDY)
}

\author{
Sepehr Eslami Arab ${ }^{1}$, Ap van Dongeren ${ }^{2}$, Peter Wellens ${ }^{2}$
}

This paper describes a laboratorium data set of wave propagation over steep slopes with large angles of incidence, and the modeldata comparison with linear and nonlinear wave models (SWAN and TRITON). The reason for this study is that the SWAN model showed an underestimation of the observed low frequency wave energy at nearshore sites in the Eastern Wadden Sea tidal inlet. Van Vledder (2010) showed that potential inaccuracies in modeling refraction over steep slopes of the tidal channel may result in observed discrepancies. The paper addresses the set up of the laboratory experiment, the novel measurement techniques and an analysis of the observed differences between models and data. The results show that there is not one single mechanism that explains the differences, but a combination of mechanisms, and perhaps other phenomena such as reflection play role.

Key words: Refraction; long waves; wave propagation; SWAN; Laboratory measurements; experimental techniques

\section{INTRODUCTION}

\section{Background}

The safety of the Dutch primary sea and flood defenses must be assessed every six years (2011, 2017, etc.). This assessment includes the Hydraulic Boundary Conditions (HBC) and the safety assessment regulations. The HBC are used to assess the safety of dikes and coastal structures. The research program to improve models and methods to perform this assessment is called SBW, which, comprises of several projects related to the hydraulic loads and strength of the coastal defenses. The general objective of the SBW is to fill the knowledge gaps in order to achieve a better estimate of the safety against failing of the primary sea and flood defenses.

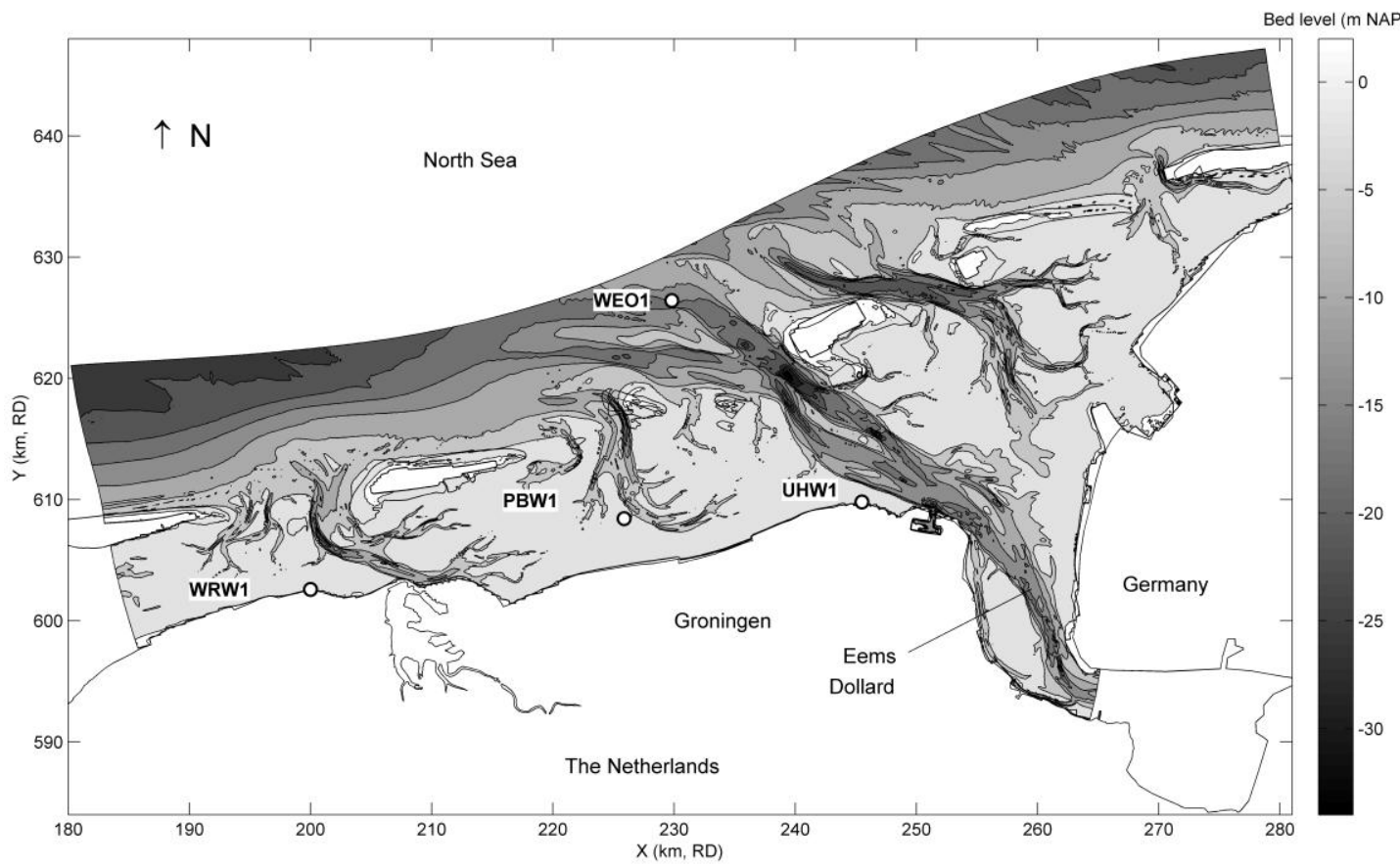

Figure 1, An overview of the eastern Wadden Sea area, showing the location of the measurement locations relative to the estuary and the north Sea, from Deltares (2011a)

\section{Problem Statement}

The SWAN model is continuously verified against the field measurements in hindcast studies, in particular, using data from the field measurement sites in the complex tidal inlets of the Wadden Sea. Figure 1 shows the eastern Wadden Sea area. The waves generated in the North Sea, penetrate through the tidal inlet and propagate along the estuary and over the tidal flats, approaching the main land Dutch coast. Wave measurements at UHW1 station (see Figure 1) showed discrepancies between the model results and the measurements in the low-frequency range which was subject to further analysis in order to improve model performance; e.g. see Groeneweg et al. (2008); van Dongeren et al. (2010).

\footnotetext{
${ }^{1}$ Deltares, presently Boskalis, Rosmolenweg 203356 LK Papendrecht, The Netherlands

2 Deltares, Rotterdamseweg 1852629 HD Delft, Netherlands
} 
A hindcast of the intense storm of 9th November 2007, showed that the low-frequency wave penetration through the tidal inlet of the eastern Wadden Sea area was underestimated. However, through a combination of artificially (numerically) limiting refraction and reducing the bottom friction dissipation better results can be obtained (e.g. see van der Westhuysen et al. (2012) and underlying reports for details). Van Vledder et al. (2010) showed that reduction of the bottom friction coefficient is supported by a recalibration of the source terms. The limitation of refraction in the model has no apparent physical basis, which warrants further research that is the subject of the current paper.

Figure 2 shows the measured wave spectrum at the Uithuizerwad (UHW1) compared to SWAN results. In the left panel, the measured spectrum (black line) is compared to SWAN results with the default settings (blue line), and to SWAN results at this location with adjusted bottom friction coefficient $\left(\mathrm{Cf}, \mathrm{jon}=0.038 \mathrm{~m}^{2} / \mathrm{s}^{3}\right.$ instead of $0.067 \mathrm{~m}^{2} / \mathrm{s}^{3}$ ). With this calibration, the amount of lowfrequency wave energy in the computation is increased. The right panel, shows the measured spectrum compared to SWAN results with the default settings (blue line) and SWAN results with reduced bottom friction and an artificial limiter for low-frequency wave refraction (red line). Artificially limiting refraction clearly improves the comparison between SWAN and the field measurements at UHW1 in the frequency range between $0.03 \mathrm{~Hz}$ and $0.20 \mathrm{~Hz}$.
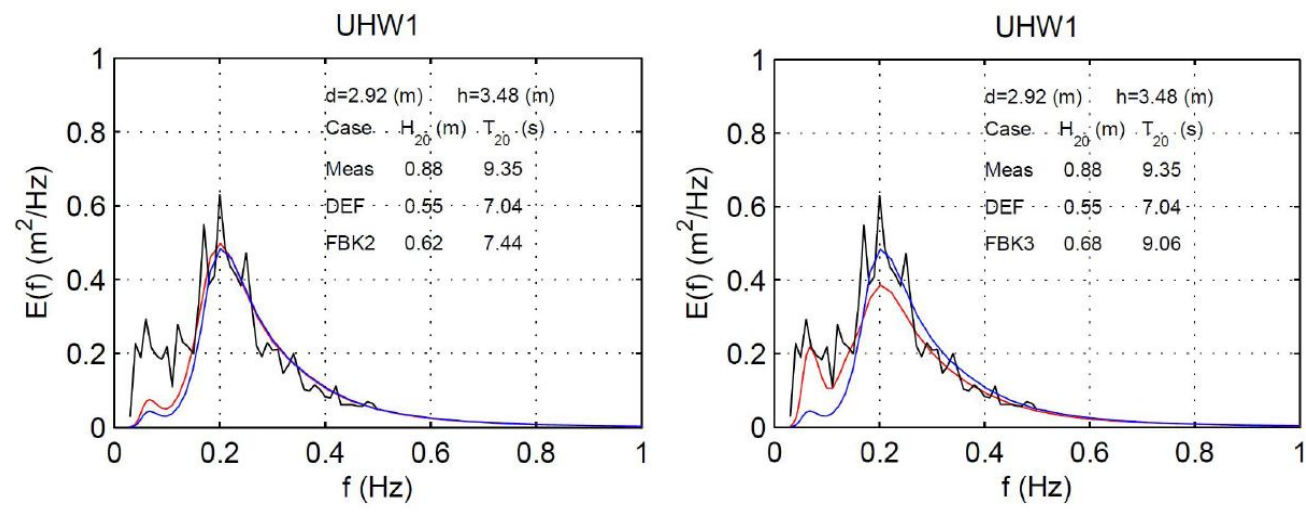

Figure 2, Measured and computed spectrum at the buoy measurement location of Uithuizerwad (UHW1); the black lines shows the measurements, blue lines are the SWAN computation with default settings, the red line in the left panel shows SWAN results with reduced bottom friction coefficient, the red line in the right panel shows SWAN results with reduced bottom friction coefficient and a limiter on refraction

Approach

Since the major research question was identified as the wave propagation, and more specifically refraction, it was decided to study the refraction of long waves over steep slopes and large angles (resembling refraction over the shoals towards the tidal flats in the estuary) in the $50 \mathrm{mX} 50 \mathrm{~m}$ wave basin of Deltares. For this purpose a physical model was constructed and the physical model results were compared to the SWAN model results. In order to understand the differences between SWAN and the measurements, a more extensive study, by using a Boussinesq model, TRITON, Borsboom et al. (2000), the laboratory experiments were numerically re-generated, and some sensitivity analysis was carried out, which provided more insight in the physics.

\section{PHYSICAL MODEL TESTS}

\section{Prototype condition}

During the storm of 8/9 November 2007, Alkyon (2008), the water level varied between NAP+1m to NAP $+4 \mathrm{~m}$. The average water level was NAP $+3 \mathrm{~m}$. However, during more severe condition in the area, a water level of NAP $+5 \mathrm{~m}$ can be expected. Therefore, NAP $+3 \mathrm{~m}$ to NAP $+5 \mathrm{~m}$ was chosen as the prototype water level condition.

The low frequency part of the measured incoming wave in the Ems Dollard estuary, was modeled approximately $1 \mathrm{~m}$, Alkyon (2009). The prototype wave frequency ranges from 0.03 to $0.15 \mathrm{~Hz}$ and a standard deviation (the width of the spectrum) was chosen as $\sigma=0.03 \mathrm{~Hz}$ (narrow-banded swell spectrum). The low-frequency waves entering the Eems estuary have directions between $300^{\circ}$ and $360^{\circ}$ (in Nautical convention), see Alkyon (2009).

\section{Laboratory condition}

The laboratory measurements were set up in a 1:40 scale. Therefore, the incoming wave height was $0.03 \mathrm{~m}$ (slightly more than prototype to ensure a sufficient signal to noise ratio), the peak wave period is 
$\mathrm{T}_{\mathrm{p}}=1.757 \mathrm{sec}, \mathrm{F}_{\text {peak }}=0.569 \mathrm{~Hz}$, and a Gauss-bell spectrum $(\sigma=0.03 \mathrm{~m})$ is chosen to generate the lowfrequency component of the prototype condition for long waves. The wave direction in the experiments was chosen such that the direction relative to the slope was comparable to the prototype condition $\left(40^{\circ}\right.$, $50^{\circ}, 60^{\circ} \& 70^{\circ}$ relative to the N-axis; see Figure 3 ). The water level varies between $0.375 \mathrm{~m}, 0.388 \mathrm{~m}$, $0.4 \mathrm{~m}$ and $0.425 \mathrm{~m}$ that correspond to $\mathrm{NAP}+3 \mathrm{~m}$ to NAP $+5 \mathrm{~m}$ in prototype. The tests were carried out for both short-crested (directional distribution $=10.2^{\circ}$ ) and long-crested (directional distribution $=4^{\circ}$ ) conditions.

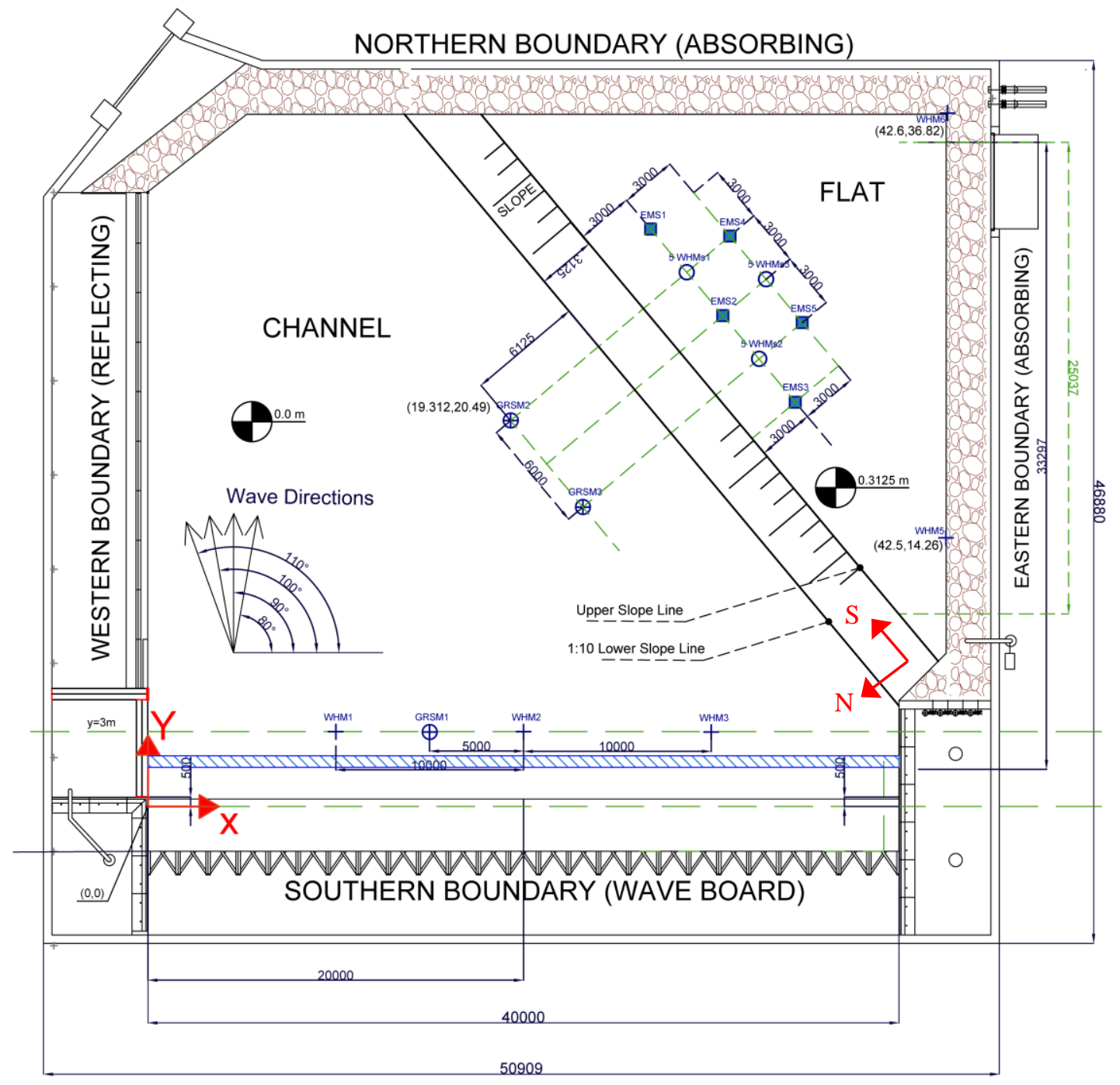

Figure 3, The experimental set-up in the Delta Basin of Deltares; the wave board is placed on the southern boundary (blue), northern and western boundaries are absorbing and western boundary is reflecting; Orepresents an array of 5 wave height meters (for wave direction) + wave height meter (WHM, measureing water level signal) $\square$ electro-magnetic velocimeters (EMS; measuring two perpendicular velocity components) $\oplus$ combined WHM and EMS resulting in 2-D spectrum (GRSM)

\section{Instrumentation and measurements}

The main purpose of the tests was to measure the wave direction at a number of locations in the channel and on the flats to determine wave refraction over the slope. Wave directions generated by the wave board, in the deeper part of the basin, were verified by a combination of "electro-magnetic velocimeters" (EMS) and "wave height meters" (WHM); hereafter this instrument is called GRSM. GRSM can provide the directional distribution of wave energy when the maximum entropy method is applied, Lygre and Krogstad (1986). In order to measure wave direction over the flat at water depth of $6-11 \mathrm{~cm}$, and to verify the consistency of the results, different techniques were applied. We chose to measure the wave direction in two parallel rows on the flat (in s-direction, see Figure 3), using different types of instruments: 
1. Measured velocities in two perpendicular directions, by means of upward looking EMS, mounted in a box that was flush with the concrete (See Figure 4). The wave direction was derived by computing the ratio of variance densities of the signals in two perpendicular directions.

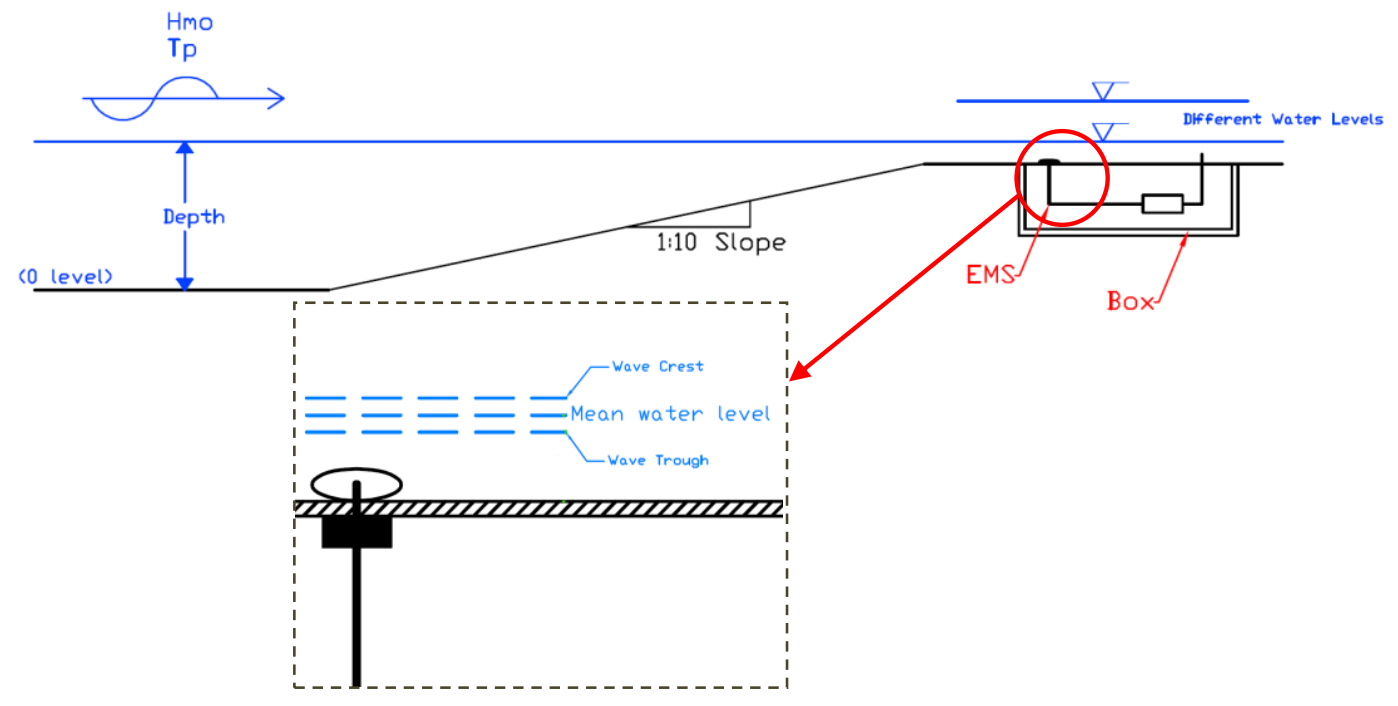

Figure 4, Conceptual drawing of the EMS box in the test basin (over the flat)

2. Using surface elevations measured with pentagonal arrays of five wave gauges, and applying the Maximum Likelihood Method, Panicker and Borgman (1971), to derive directional spectra and thus directions.

3. By comparing the cross-correlation of water surface signals of two wave gauges over the flat to derive the phase lag, which, combined with the known orientation of the two gauges, can provide the direction of wave propagation (Deltares, 2010a).

Figure 5 below shows an overview of wave propagation over the slope towards the flat, acting on the measurement facilities.

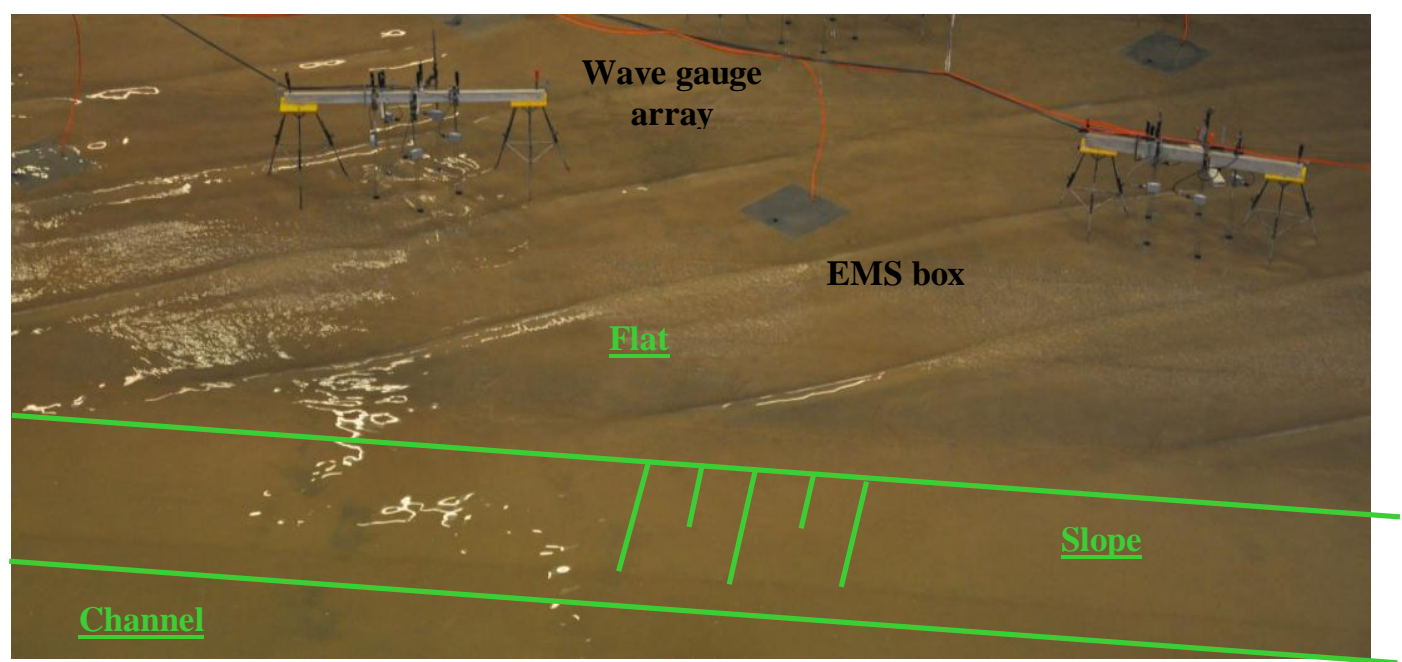

Figure 5, An overview of the instruments placed in the basin under wave action

Apart from the abovementioned instruments, multiple wave gauges were placed at different locations around the basin to recognize laboratory effects such as seiching, reflection etc. Figure 7 gives an overview of the tests and shows a refraction pattern over the slope; note the curvature of the waves towards the slope.

In the present article, for sake of brevity, only the results of the EMS measurements are presented. Three different measurement and post-processing techniques showed good consistency in the observed trends. 


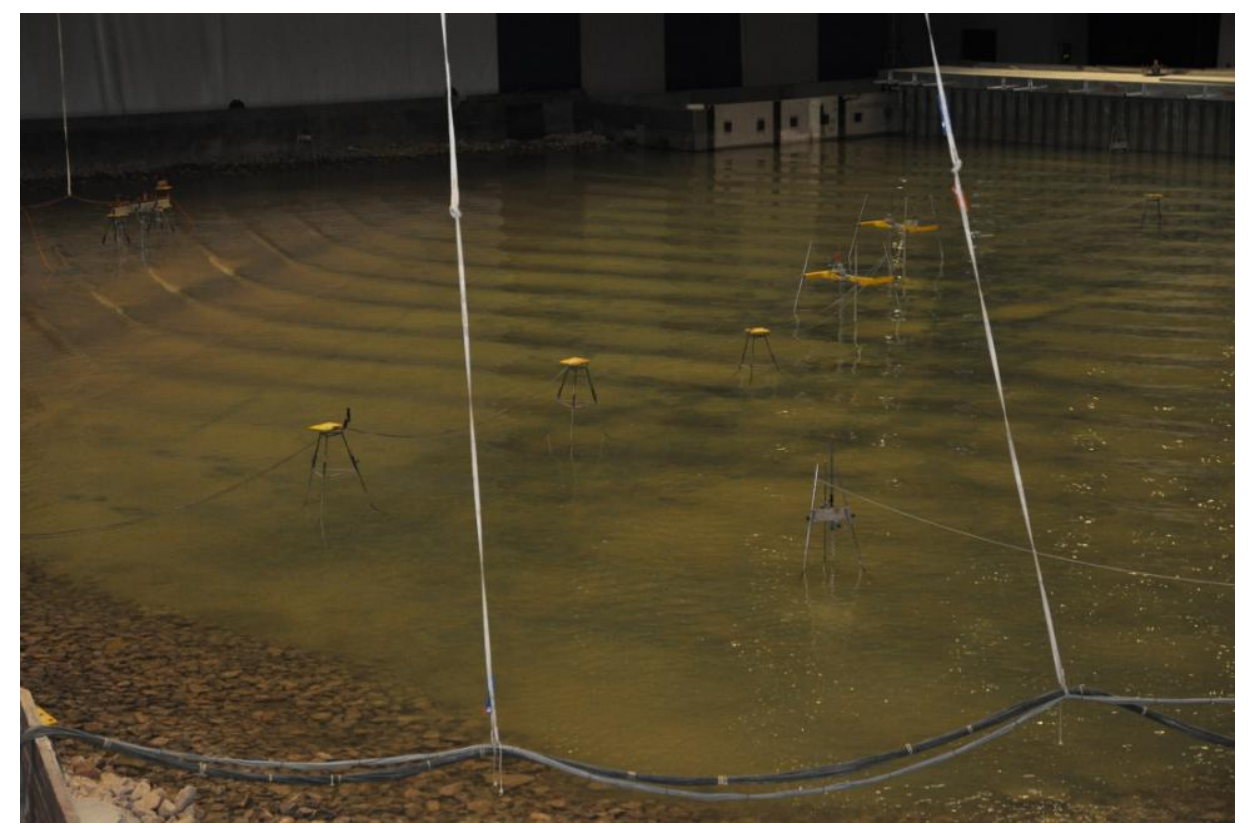

Figure 6, A Photograph of a test showing the refraction pattern over the slope in the Delta Basin

An EMS probe measures time series of water particle velocities in two perpendicular directions (see Figure 7 for the velocities in $\mathrm{x}$ - and in y-directions in the coordinate system of the basin). From these signals wave directions were derived. The following procedure was applied:
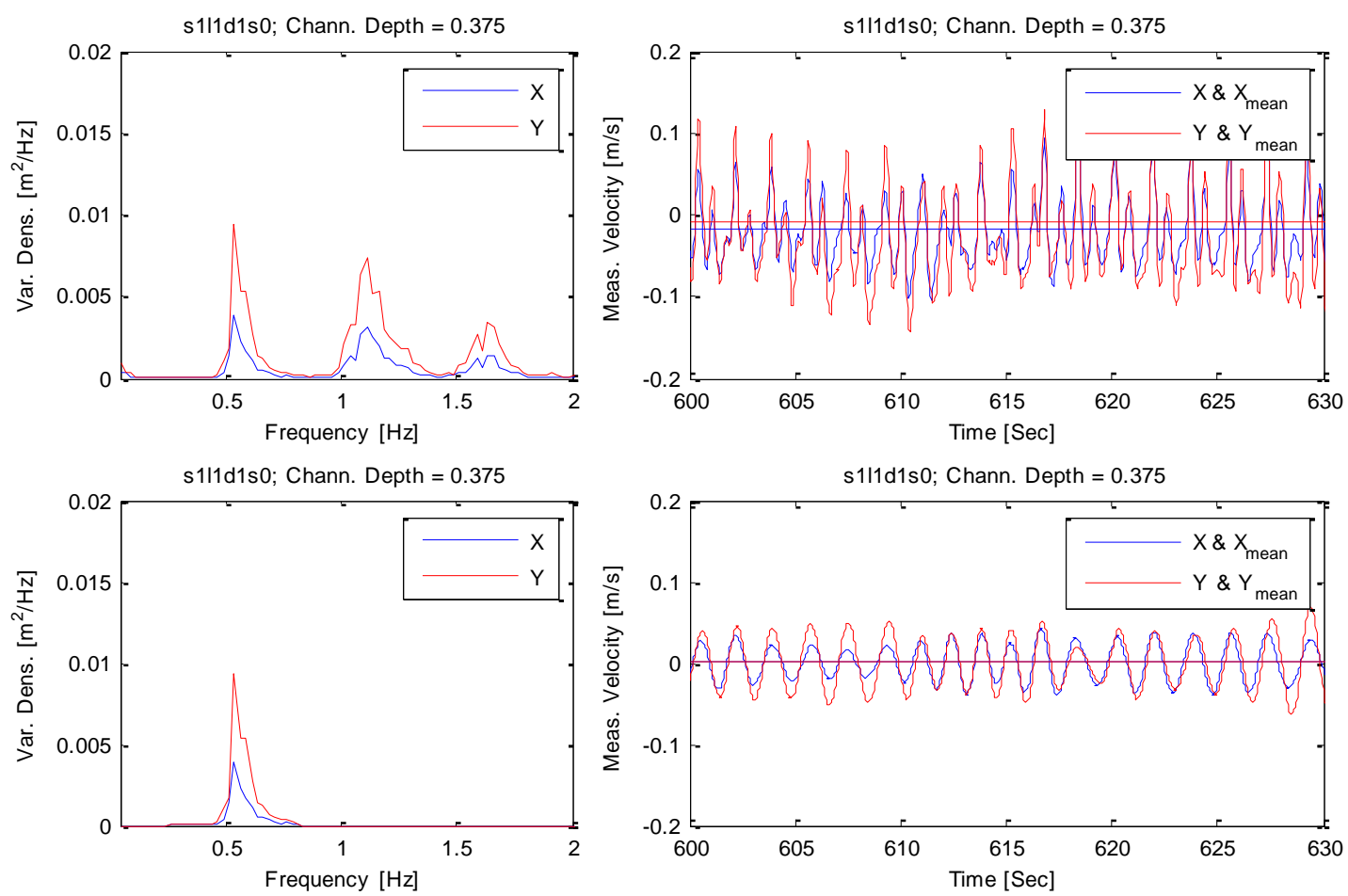

Figure 7, Measured (upper left) and filtered (lower left) variance density spectra of velocities in $x$ - and in ydirection and the associated time series of the measured (upper right) and filtered (lower right) spectra.

1. The variance density spectrum of each of the velocity time signals was computed.

2. A band pass filter was applied to the spectra, in order to retain only the energy between $0.25 \mathrm{~Hz}$ and $0.8 \mathrm{~Hz}$ around the peak frequency (primary harmonic). Figure 1 shows an example of the measured and the filtered signals and spectra for the location EMS1 in a test with depth of $0.375 \mathrm{~m}$, and waves approaching with $40^{\circ}$ (relative to the $\mathrm{N}$-axis). Note the energy transfer to the higher 
harmonics. Since capturing the physics to this level of non-linearity with the SWAN model was not possible, it was decided to focus on the energy of the peak frequency. This would also improve the signal to noise ratio.

3. Transformation of filtered spectra from frequency domain to time domain.

From the filtered time signals, RMS-values of the two velocity components are determined. From the RMS-values the wave direction $\alpha$ can be determined, as in Eq. 1 below:

$$
\alpha=\arctan \left(\sqrt{\left(\sum_{i=1}^{N} V_{y_{i}}^{2}\right) / N} / \sqrt{\left(\sum_{i=1}^{N} V_{y x_{i}}^{2}\right) / N}\right)
$$

where $V_{x}$ and $V_{y}$ are the measured velocity components, $N$ is the number of time steps, and $\alpha$ is the wave propagation direction with respect to the basin xy-coordinate system. By subtracting a value of $40^{\circ}$, the direction is derived with respect to the NS-coordinates.

In order to suppress the laboratory effects, the northern and eastern boundary of the Delta basin are spending beaches, absorbing the waves (to avoid reflection). Part of the wave board was de-activated, to avoid reflection in the basin (see Figure 9, and section for Boussinesq modeling for better visualization). The wave board is equipped with active reflection compensation (ARC) system, absorbing the reflected waves at the wave board. Note that due to large experimental area $(50 \mathrm{mX} 50 \mathrm{~m})$, laboratory (edge) effects in the measurement area are significantly reduced.

\section{Results and comparison with SWAN}

The SWAN model was first run to reproduce the experiments. Simulations were carried out for all the experiments with limited modeled physics, in order to focus solely on wave propagation. Physical modeling settings of SWAN, such as triad and quadruplet wave-wave interactions, white-capping, diffraction and bottom friction dissipation terms were deactivated. The only active processes were wave propagation and depth-induced wave breaking. These simplifications are justified, because they were shown to have limited influence on the low-frequency energy loss in the Eastern Wadden Sea simulations in Deltares (2009b) and Alkyon (2009). Note that the comparison of laboratory and SWAN model results is made for the mean direction of the spectral energy of the primary harmonic. Energy transfer to higher harmonics is deactivated in SWAN simulations and in the measurements, the energy of the higher harmonics is band-pass filtered. Eq. 2 below presents the definition of mean wave direction output in SWAN; this definition, although not identical, is similar to the one used to derive wave direction from the measurements. Both wave directions (SWAN and measurements) derive direction from a ratio of energy density in $\mathrm{X}$ and $\mathrm{Y}$ coordinates.

$$
[D I R]=\arctan \left[\int \sin (\theta) E(\sigma, \theta) d \sigma d \theta / \int \cos (\theta) E(\sigma, \theta) d \sigma d \theta\right]
$$

Where, DIR is the keyword for wave direction output of SWAN, E is the energy density, $\sigma$ and $\theta$ are frequency and direction of energy propagation.

The mean wave direction over the flat from the experiments and from the SWAN computations versus the generated wave directions are plotted together in Figure 8; long-crested waves on the left panel and short-crested waves on the right panel. Each blue and red line of the same line-style refer to the tests result of a specific water level for various wave directions. Focusing on the left panel (longcrested waves) and looking at the two upper lines (dash-dotted red and blue), we see that the difference in the wave direction is not more than $5^{\circ}$, which is a good performance of the SWAN model. The other pairs of measured and computed wave directions show more or less similar behavior (also for shortcrested waves). Note that larger wave direction in SWAN implies stronger refraction and vice versa .

Apart from the good performance of SWAN model, a consistent trend can also be traced in lab and model results. SWAN shows a smaller wave angle over the flat for the small approach angles $\left(40^{\circ}\right.$ $\left.50^{\circ}\right)$, meaning a small overestimation of refraction. For larger approach angles $\left(60^{\circ}-70^{\circ}\right)$, SWAN shows a slightly larger wave angle over the flat (underestimation of refraction). This trend is consistent for all different water levels, and for both long-crested and short-crested waves (especially for the large approach angles). This trend only becomes important when we do not know how it develops towards larger approach angles. In fact, the trend seems to grow for the larger approach angles. On the other hand, from the non-linear theory, it was envisaged that due to increase of phase speed over the flat (compared to linear theory), refraction is less for larger approach angles, which was not observed in the experiments. The was also seen in the other measurement methods. Two other measurement and postprocessing techniques confirmed the observed trend by EMS. This provided confidence on the measurements results. Note that for four EMS's, assuming Student t-distribution for the small number of samples, a confidence band of $2.664^{\circ}$ was calculated (as shown in Figure 8). The observed differences are consistent and approximately within the confidence band. 

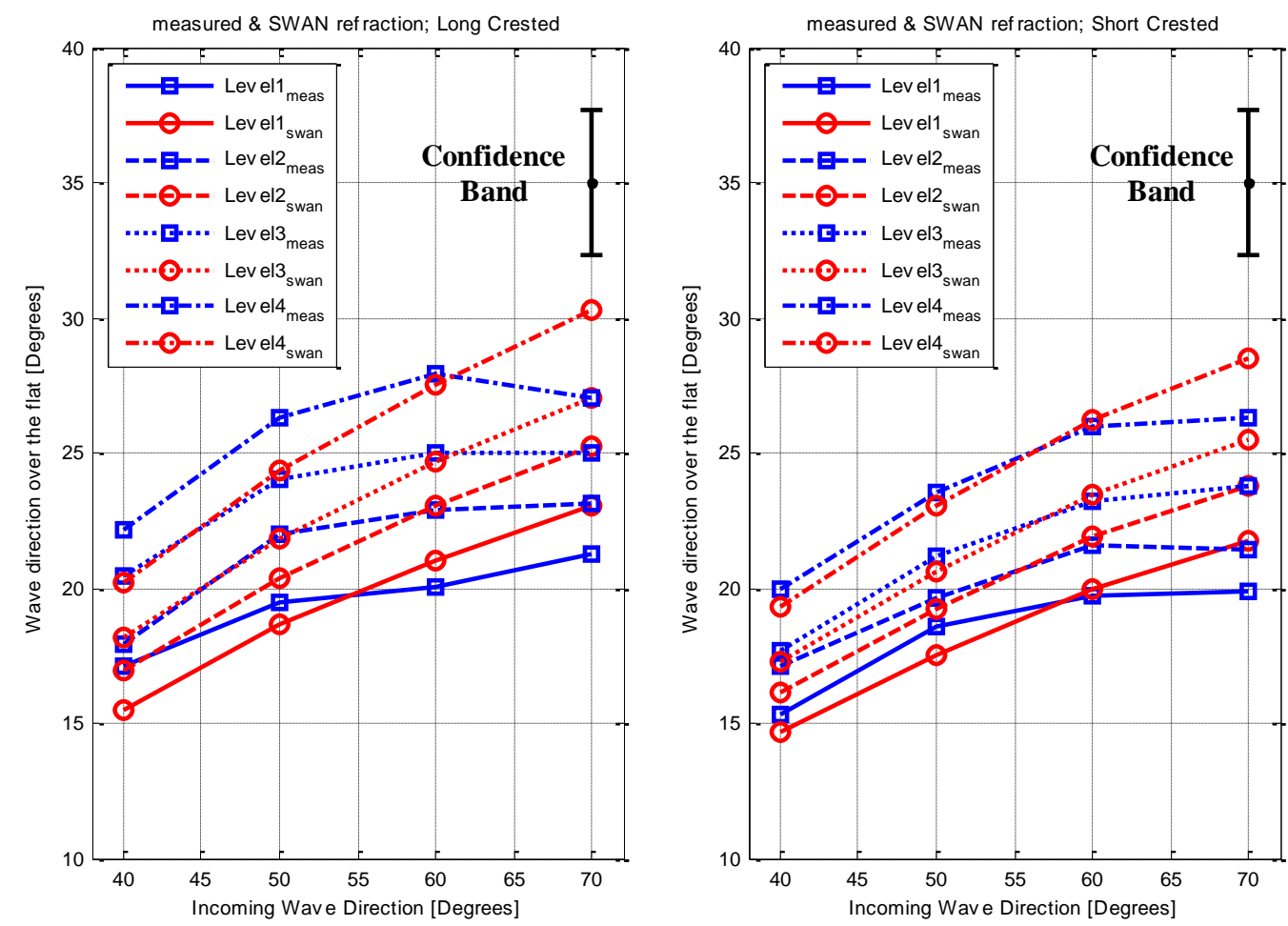

Figure 8, Mean wave direction over the flat in the experiments, compared to the mean wave direction over the flat in SWAN for different water levels. The left panel shows the tests, in which longcrested waves were generated in the basin and the right panel shows the cases with shortcrested waves

\section{APPLICATION OF A BOUSSINESQ MODEL}

\section{Modelling with TRITON}

The observed trend, and the discrepancies with the SWAN model (linear theory), is investigated further with a more complete model, the Boussinesq wave model TRITON, Borsboom et al. (2000). In this section, the model is verified against the laboratory measurements and at a later stage a sensitivity analysis is carried out to study the potential physical explanations of the observed trend.

The TRITON simulations are performed in a square, $40 \mathrm{mx} 40 \mathrm{~m}$ computational domain with equidistant grid points of size $d x=d y=0.1 \mathrm{~m}$. The simulation time was $400 \mathrm{~s}$ with a time step of $0.1 \mathrm{~s}$ (Courant number smaller than 1). The duration corresponds to approximately 200 waves. Due to computation time restrictions, longer simulations were not performed. A time-series of water level was imposed to the western boundary that correspond to the Gauss-bell spectrum in the experiments.

Figure 9 shows the computed water level changes by TRITON. Note that the coordinate system of TRITON is rotated by $90^{\circ}$ with respect to the xy-coordinate system in the Delta basin. Looking at the western boundary where the waves are generated (wave board), it shows how partially deactivated wave board minimized the laboratory (edge) effects, resembling the laboratory experiment and providing some visual impression.

Figure 10 shows the wave energy distribution. In the upper left panel, the spectrum of surface elevations at the wave board is compared to the incoming wave in TRITON $\left(\mathrm{H}_{\mathrm{m} 0}=0.03 \mathrm{~m}\right)$. The bottom four panels show the spectra measured and computed by TRITON at "5WHM1" (a measurement station, array of 5 wave gauges; See Figure 3 for the exact location), over the flat, for four different incoming wave directions. Due to non-linearities, there is a significant energy transfer to higher $\left(2^{\text {nd }}\right.$ and 3rd) harmonics. 

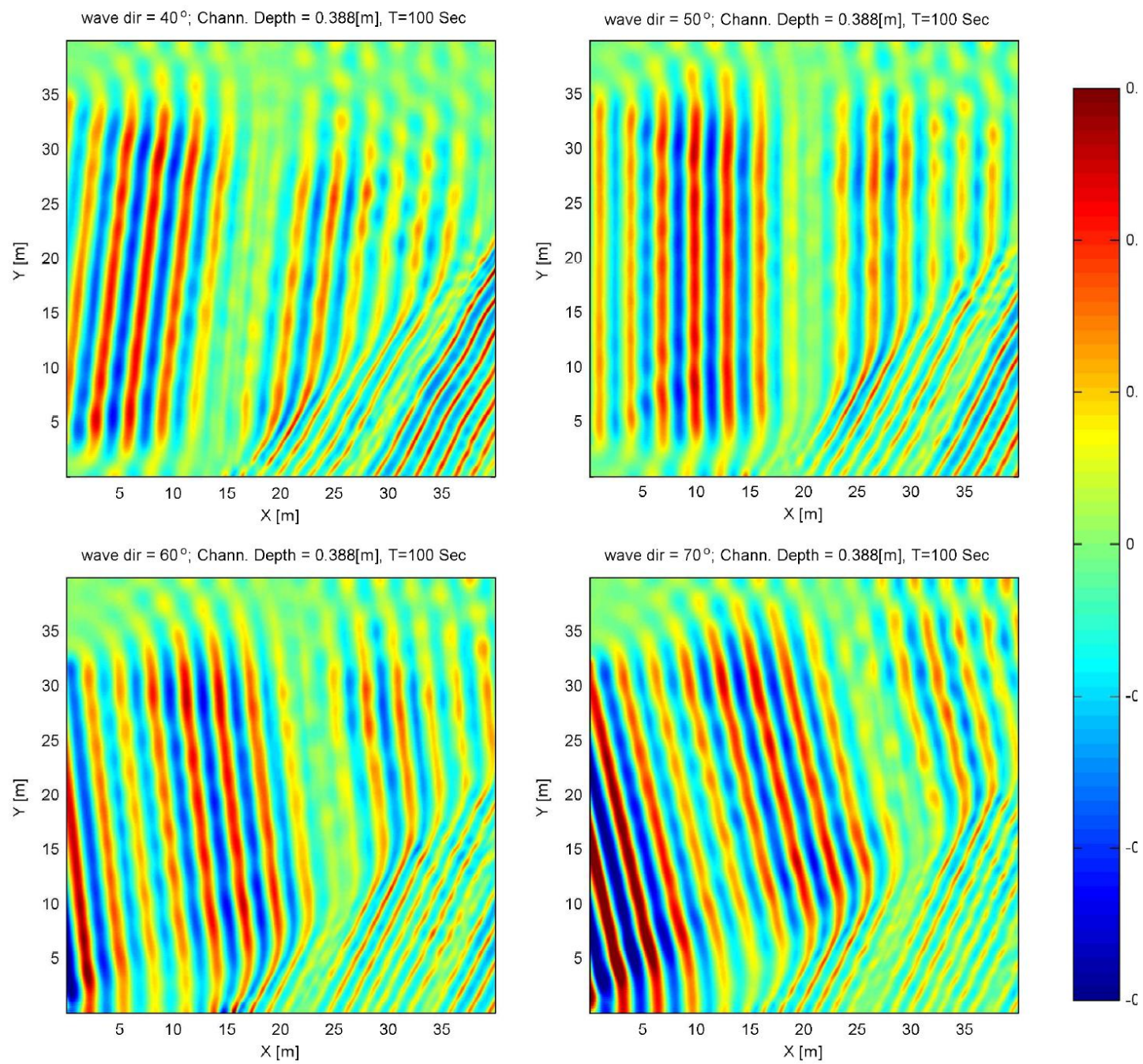

Figure 9, Water surface [m], simulated by TRITON, after 100 second of simulation, for four different directions, water level of $0.388 \mathrm{~m}$, the generated wave directions are given relative to the slope normal
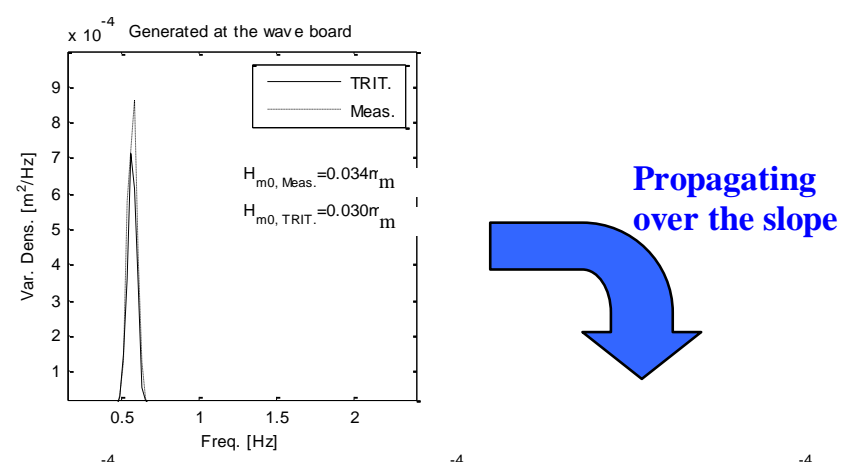

Channel Depth $=0.375 \mathrm{~m}$
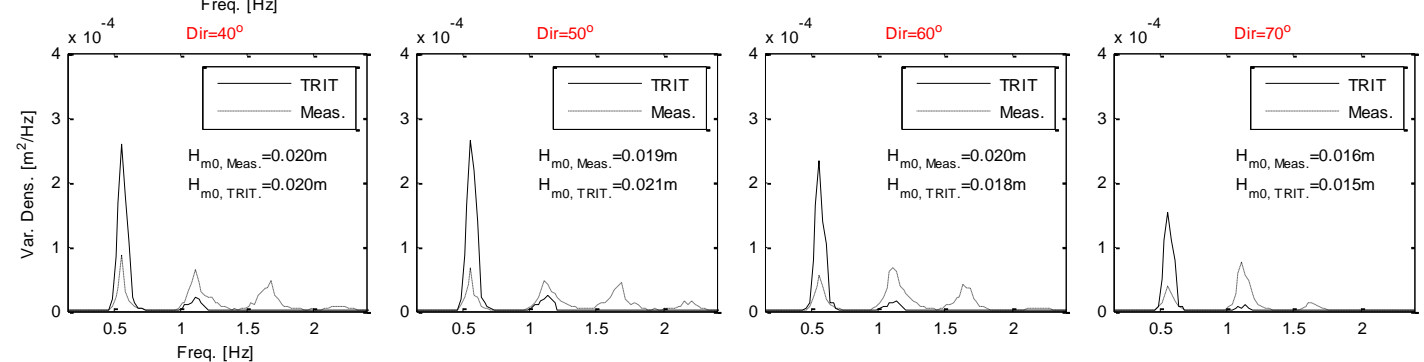

Figure 10, Measured and computed (by TRITON) wave spectra in the channel (top left panel), and over the flat (the lower four panels) for the four incoming wave directions 
The comparison between TRITON and the experiment showed that TRITON under-predicts the transfer of wave energy to higher harmonics as was expected due to limited non-linear terms in the Boussinesq model. From the values of $\mathrm{H}_{\mathrm{m} 0}$ over the flat, however, we find that the total amount of wave energy in TRITON is well represented, and that dissipation due to breaking is modeled accurately.

\section{Computed wave direction with TRITON}

Figure 11 presents the wave directions over the flat in TRITON compared to SWAN and the experiment. Wave directions are with respect to the NS-coordinate system. Each panel in Figure 11 is for a different water level. From Figure 11, we find that the wave directions over the flat in TRITON are not entirely equal to the observed wave directions. However, compared to SWAN results, a similar trend, with less refraction in smaller approach angles and stronger refraction with larger approach angles was also generated. Compared to TRITON, SWAN overestimates refraction for the incoming wave directions between $40^{\circ}$ and $60^{\circ}$ and underestimates refraction for large incoming wave direction of above $60^{\circ}$. These results show that the Boussinesq model is capable of re-generating the observed trend and can be used for further investigation.
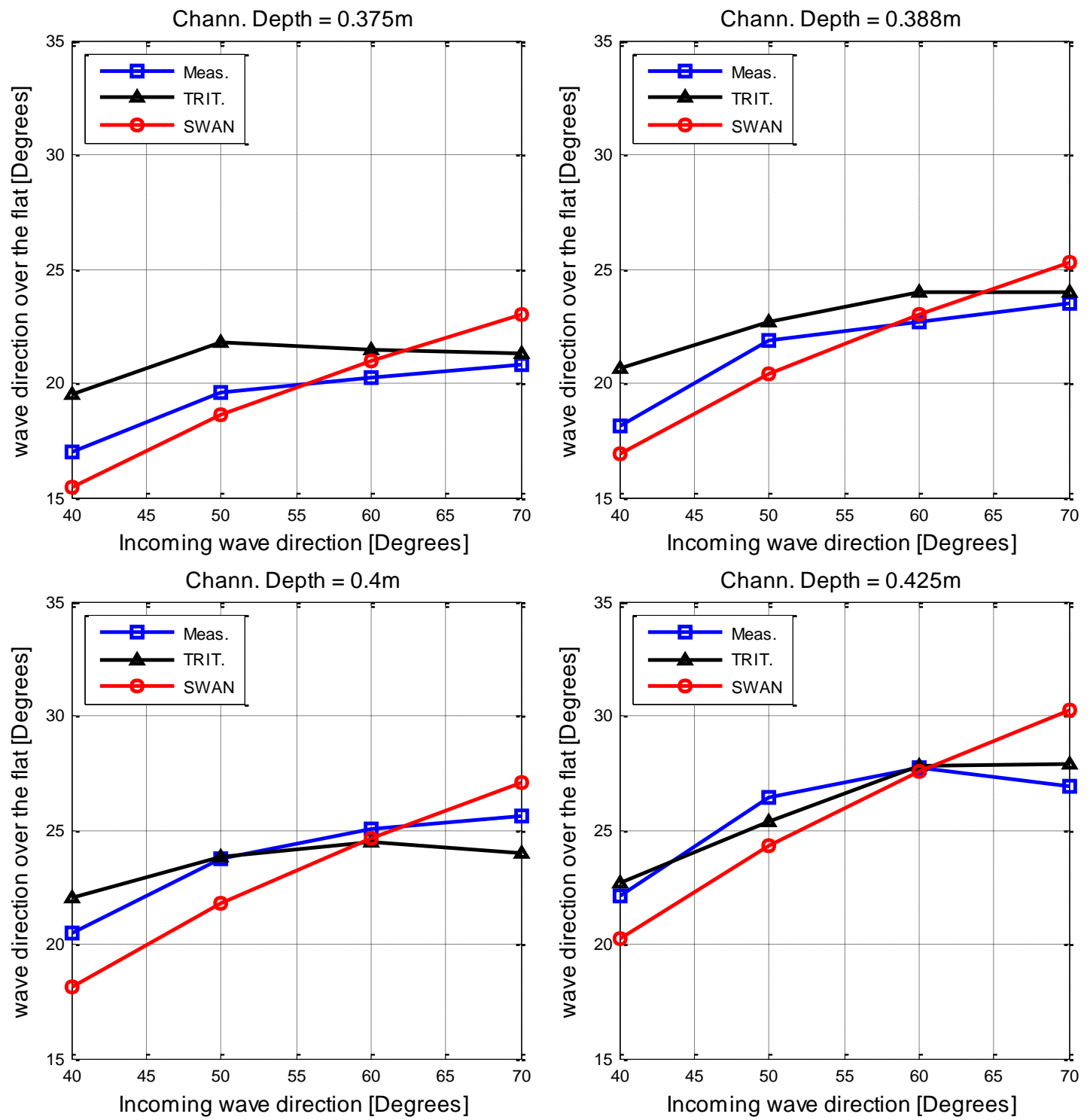

Figure 11, Wave directions over the flat as a function of incoming wave direction in the channel. SWAN results are compared to the experiment and to TRITON for four different water levels

\section{Further investigation and sensitivity analysis}

There were different hypotheses for the observed differences in wave direction between SWAN and the experiment/TRITON: 
1. Wave breaking over the slope towards the flat could generate wave-driven currents, which may interact with wave refraction. Additional refraction due to currents could potentially lead to the mismatch between SWAN and the experiment. The effect of current on wave refraction over the slope is assessed using coupled wave-current simulations with Delft3D-Flow module.

2. Waves over the slope become steeper. There, the assumption of linear wave theory for the dispersion relation underlying the model equations in SWAN may not be valid. Simulations in TRITON were performed with very small wave heights, in order to minimize non-linear effects, to assess the effect of wave steepness on refraction in TRITON.

3. The bathymetry gradient may have an influence on wave refraction. It is known that the model equations in SWAN resemble the mild-slope equation. A slope of 1:10 may be too steep for SWAN to model accurately. Therefore, simulations in TRITON were performed with reduced slopes of 1:20 and 1:30 to investigate the effect of bed slope on wave refraction.

\section{Effect of wave current interaction}

To determine the effect of wave-driven currents on refraction, the combined models Delft3DFLOW and Delft3D-WAVE (SWAN) were used in this study. The Delft3D-WAVE module runs the SWAN model to determine the wave field. Where wave energy dissipates as a result of breaking, a force on the water column is exerted. The force due to breaking is computed from SWAN as radiation stress and is included as a source term in the Delft3D-FLOW module to compute wave set-up and wave-driven currents, see Longuet-Higgins and Stewart $(1960,1962)$.

Delft3D was run for 45 minutes of simulation, with time steps of 0.3 seconds (Courant number varying between 1 5). The simulation domain is identical to the SWAN domain (see Figure 12). Closed boundaries were defined in the FLOW module. The bottom roughness in the FLOW-module was modeled by a roughness height of $1.8 \mathrm{~mm}$, representing a smooth concrete surface in the WhiteColebrook formulation. During the 45-minute simulation time, the WAVE-module was run every 2 minutes to determine a new wave field that was fed back to the FLOW-module. Stationary results in terms of mean current velocities and wave heights were obtained after approximately 20 minutes of simulation time.

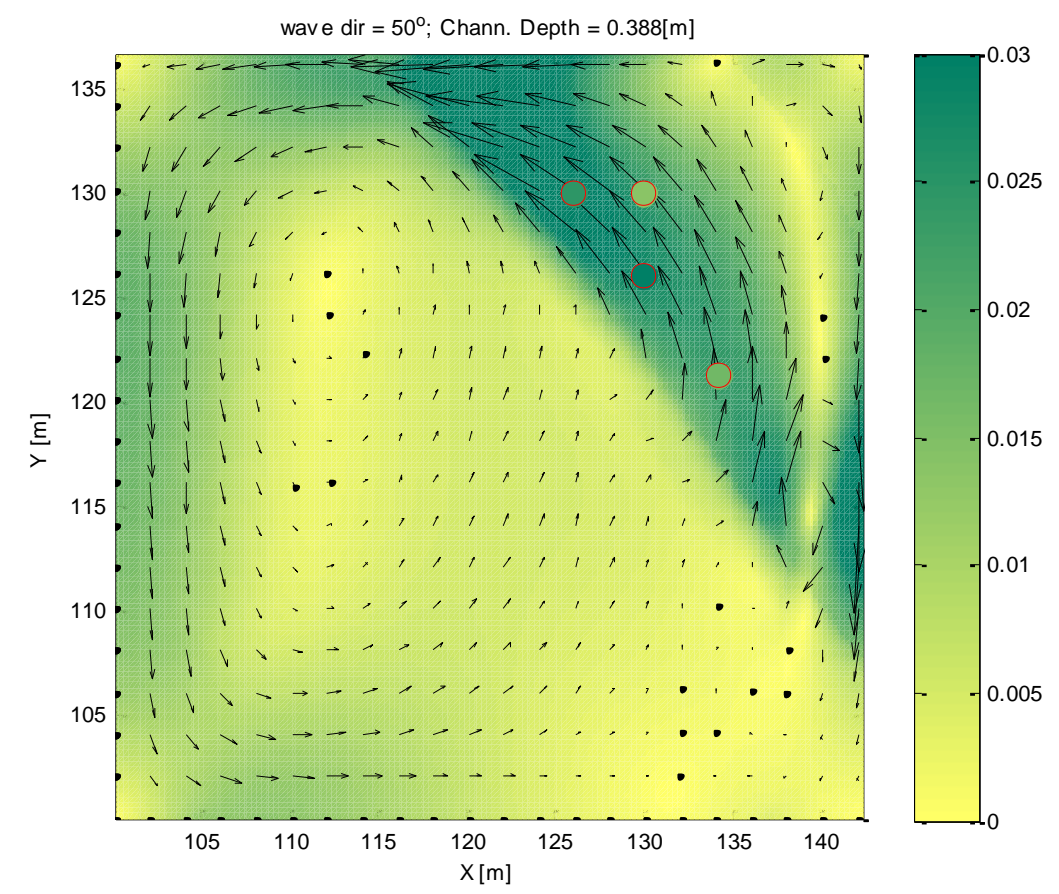

Figure 12, Depth-averaged wave-driven current pattern (in $\mathrm{m} / \mathrm{s}$ ) in the basin, determined with Delft3D.Timeaveraged velocities from the experiment at the measurement locations are shown in the red circles

Figure 12 shows an example of the mean current pattern due to wave breaking after $45 \mathrm{~min}$ of simulation time. The incoming wave direction in this case was $50^{\circ}$ with respect to the ns-coordinate system. The absolute value of the depth-averaged flow velocity is indicated with colors; the direction of the flow velocities is indicated by arrows. Figure 12 also shows time-averaged velocities from the experiment in red circles with the similar color scale as the Delft3D results. The Delft3D results do not 
compare exactly with the experimental results, but the order of magnitudes at multiple locations are in satisfactory agreement. The maximum velocity in the basin is in the order of $0.03 \mathrm{~m} / \mathrm{s}$, in both the measurements and in the Delft3D simulations. The figure shows that a large eddy develops in the Delta basin. The eddy goes in counter-clockwise direction and is centered approximately at $[\mathrm{x}, \mathrm{y}]=$ $[115 \mathrm{~m}, 127 \mathrm{~m}]$. Large velocities can be observed along the Eastern boundary in Southward direction.

The mean wave-driven currents affect wave refraction over the slope. The differences between SWAN results for refraction with currents and without currents is shown in Figure 13. The wave directions over the flat with currents are labeled 'Delft3D'. Figure 13 also shows the wave directions over the flat for TRITON and the measurements in each panel. The different panels are for four different water levels. Wave directions are with respect to the ns-coordinate system. From Figure 13, we find that the effect of wave-driven currents on refraction is relatively small; waves are refracted one degree less on average in SWAN when currents are present. This can be explained by comparing the maximum observed mean current velocity to the phase velocity of the waves over the flat. The phase velocity at the peak frequency over the flat for the smallest water depth is approximately $0.75 \mathrm{~m} / \mathrm{s}$. The maximum mean current velocity is roughly $0.03 \mathrm{~m} / \mathrm{s}$. For this reason, the effect of current on the flat cannot be more than 5\%. Wave-induced currents do not explain the differences in wave direction between SWAN and the measurements.
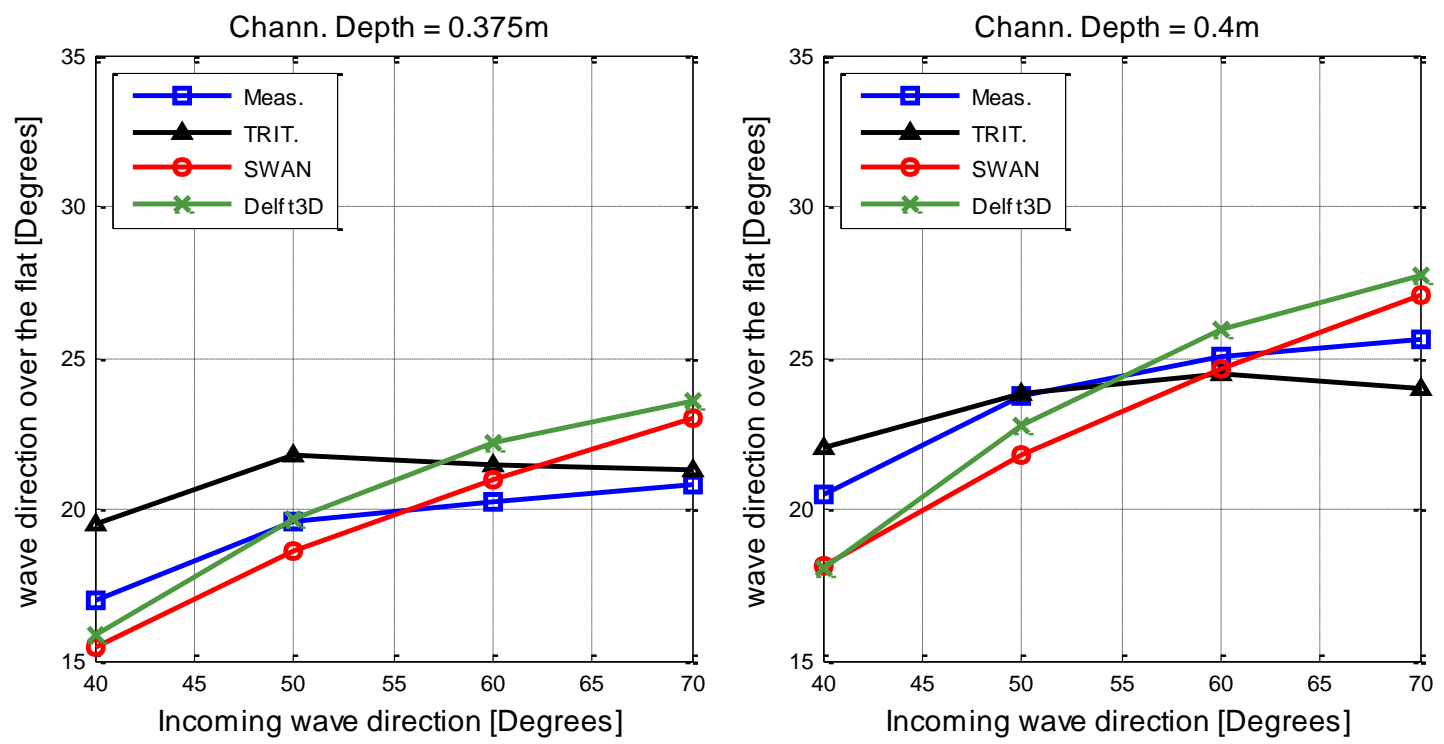

Figure 13, Wave directions over the flat as a function of incoming wave direction in the channel. Delft3D results with waves and wave-driven currents are compared to SWAN without currents, TRITON and the experimental results

\section{Effect of non-linearity}

From non-linear theory it was expected that, higher phase speed compared to that of linear theory should result in less refraction, contrary to the findings of experiments (especially for the largest approach angles). In order to study the effect of nonlinearity, we first diminish nonlinearity, by reducing the wave height in TRITON simulations for 100 times. If non-linearity has significant influence in the observed trend, reduced nonlinearity should lead the TRITON (or experiment) trend to that of SWAN (linear theory). The wave directions computed by TRITON are presented in Figure 14 below.

Figure 14 shows a comparison of measurements, SWAN, TRITON and modified TRITON (reduced wave height). The wave directions in TRITON are somewhat closer to the wave directions in SWAN (mostly for smaller approach angles), when the wave height is reduced for 100 times, but the trend in the differences between SWAN and TRITON is not changed. From the analysis with the reduced wave height in TRITON, we conclude that non-linearities do not explain the differences between SWAN and the experiments. 

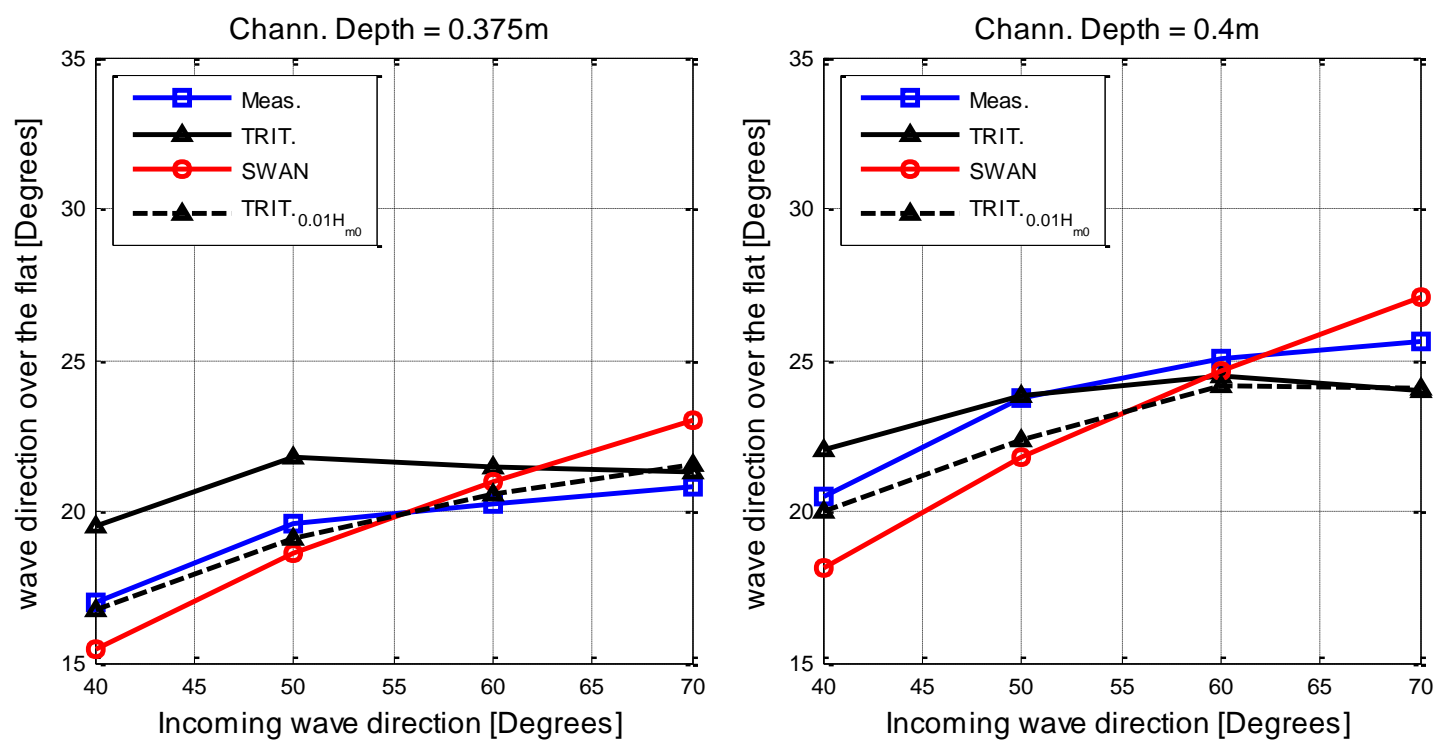

Figure 14, Wave directions over the flat as a function of the incoming wave direction in the channel for different incoming wave directions and water levels. TRITON simulations with a reduced wave height are compared to SWAN and the experiment

\section{Effect of bathymetry gradient}

The gradient of the bathymetry is not accounted for in Snell's Law for wave refraction. From derivation of mild-slope equations It is known that there is an effect of bathymetry gradients on wave propagation; see Berkhoff (1972). In this section, TRITON is used to study the effect of the slope gradient on refraction. TRITON simulations were performed, in which the 1:10 slope between the channel and the flat is replaced by a 1:20 and a 1:30 slope. The results are presented in Figure 15.
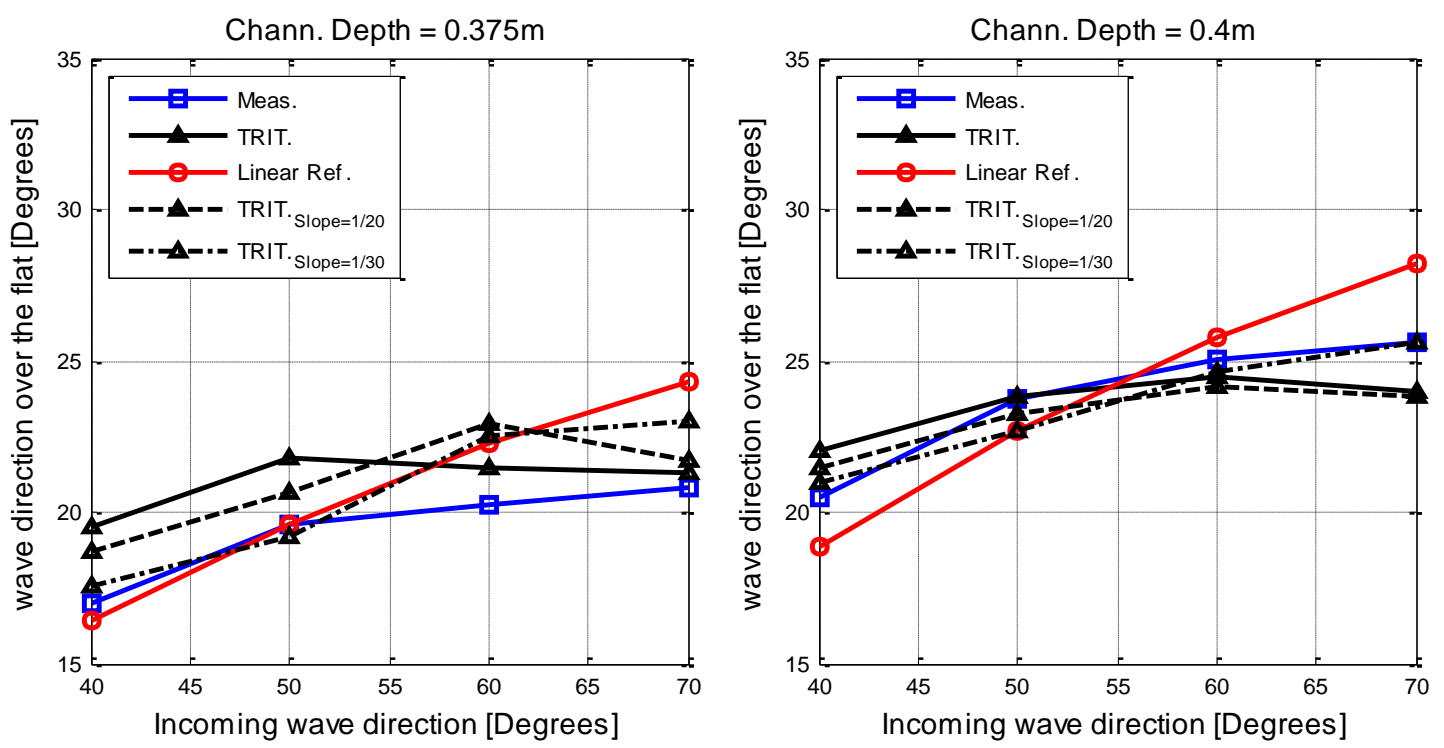

Figure 15, Wave direction over the flat for different incoming wave directions and water levels for the TRITON simulation with a reduced bathymetry gradient

Figure 15 shows the wave direction over the flat as a function of incoming wave direction and water level. Results of TRITON simulations with reduced slope gradients are compared to the experiment and to SWAN. TRITON results for the wave direction over the flat are closer to the SWAN results when the gradient of the slope is reduced. Similar to the simulations with reduced wave height, the TRITON line is somewhat closer to that of SWAN, but the trend has not changed for the largest approach angle. We can conclude that the bathymetry gradient does not explain the trend in the differences in wave direction over the flat between SWAN and the experiment. 


\section{Effect of bathymetry gradient}

Combined simulations with milder slope and reduced wave height were performed with TRITON. These simulations (presented in Figure 16) showed that TRITON trend converges to the SWAN trend, but the difference in the largest approach angle did not improve.
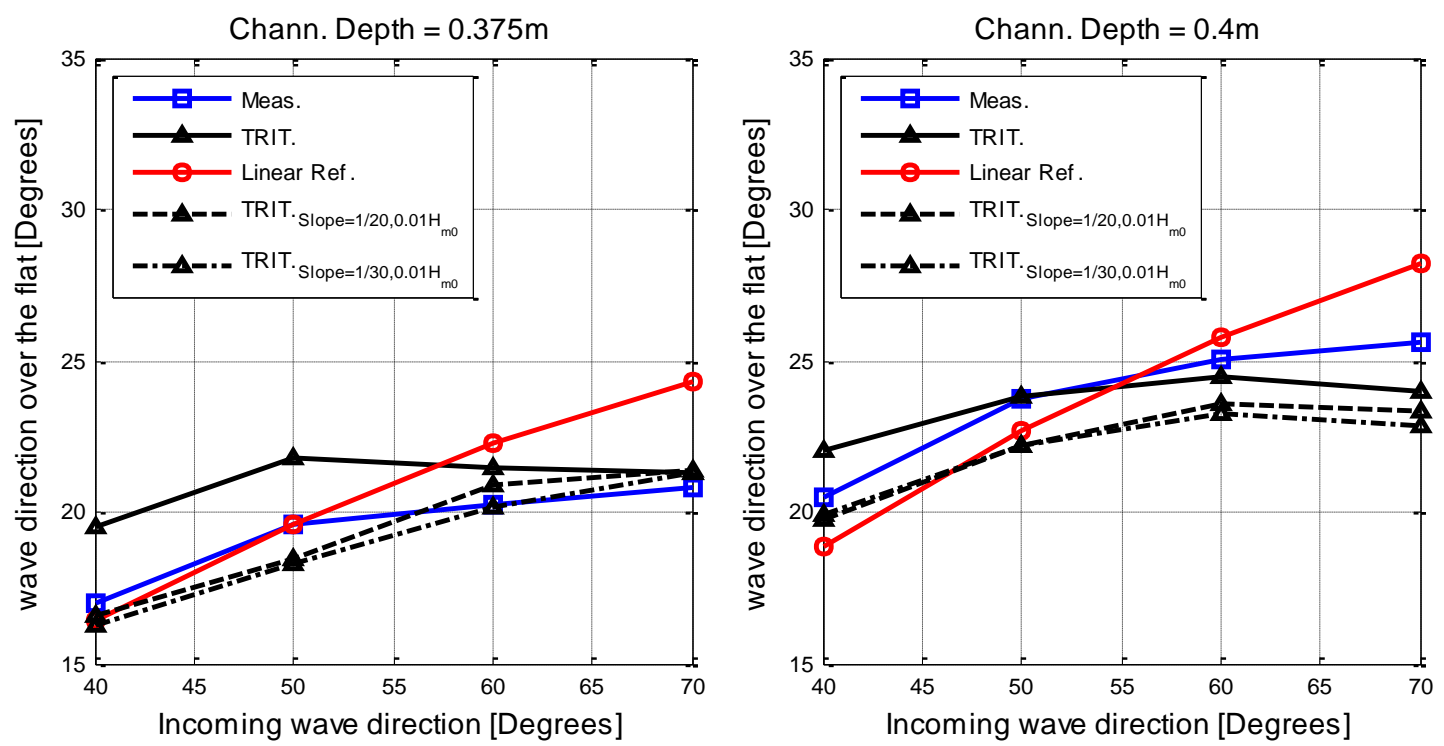

Figure 16, Wave direction over the flat for different incoming wave directions and water levels. The wave directions from TRITON simulations with reduced slope and wave height are compared to the experiment and to SWAN

\section{DISCUSSION}

In order to explain the observed differences between SWAN computations and the measurements in the eastern Wadden Sea area, where the low frequency energy, in a hindcast study of the storm of $8^{\text {th }}$ and 9th November 2007 was underestimated, an extensive physical model study was carried out. The physical model study focused on wave propagation, and more specifically refraction of low frequency waves, over steep slopes of the Ems Dollard estuary towards the tidal flats.

Some novel measurement techniques were developed during the tests. Several measures were taken to minimize the laboratory effects. Different measurement techniques and post-processing methods were applied to ensure the accuracy of measurements. In total, three different methods confirmed the observed trends in the measurements, out of which one is presented in this paper.

During the tests, wave refraction over a steep slope (1:10), from deep water towards shallow water was measured, and compared to the SWAN results. Comparison between SWAN and the measurements showed a good performance of SWAN (less than $5^{\circ}$ difference). This provided some confidence on the model performance. However, the observed trend in discrepancies of SWAN and measurements were different than expected. SWAN showed stronger refraction for smaller approach angles $\left(40^{\circ}-50^{\circ}\right)$, but underestimated refraction for the largest approach angle $\left(70^{\circ}\right)$.

The abovementioned trend, although not yet significant, raised questions on development of the trend towards larger angles. If the observed trend would develop more significantly for the larger approach angles, then an important knowledge gap raises on this specific topic.

Different scenarios were considered. One of the laboratory effects that could result in the observed trend, was identified as the wave-dirven current. Coupled simulations of Delft3D-Flow with SWAN showed that the circulations generated in the basin due to wave dissipation, do not lead to the observed trend. Therefore, applying a Boussinesq wave model, a more in-depth analysis was carried out on the physics. TRITON model was verified against the experiments and looking at the wave angles, TRITON was capable of generating a similar trend compared to the measurements. The present nonlinear terms in TRITON was not sufficient to fully resolve energy distribution in the frequency domain, but enough to accurately maintain the energy balance, and still capture some of the non-linear effects.

Since separation of physical processes in a Boussinesq model is not as easy as a phase-averaged model (e.g. SWAN), a sensitivity analysis was carried out to investigate possible explanations. Neither non-linearity nor bottom slope (i.e. both effects are missing in the linear approach) did not solely explain the observed trend. 
Focusing on the experiments, studying the wave height variation in different tests and at different locations showed that wave height over the flat was consistently reduced for the largest approach angle. This was found by analyzing the signals of 15 wave gauges over the flat. Figure 17 shows that this reduction of wave height was observed consistently in all water levels and locations. Considering this wave height reduction, and applying the existing non-linear phase speed formulations, e.g. Walker (1974, 1976) or Kirby and Dalrymple (1986), did not result in a significant difference on angle of wave refraction. Therefore, it was concluded that the effect of phase speed and this reduction of wave height does not explain the observed trend.
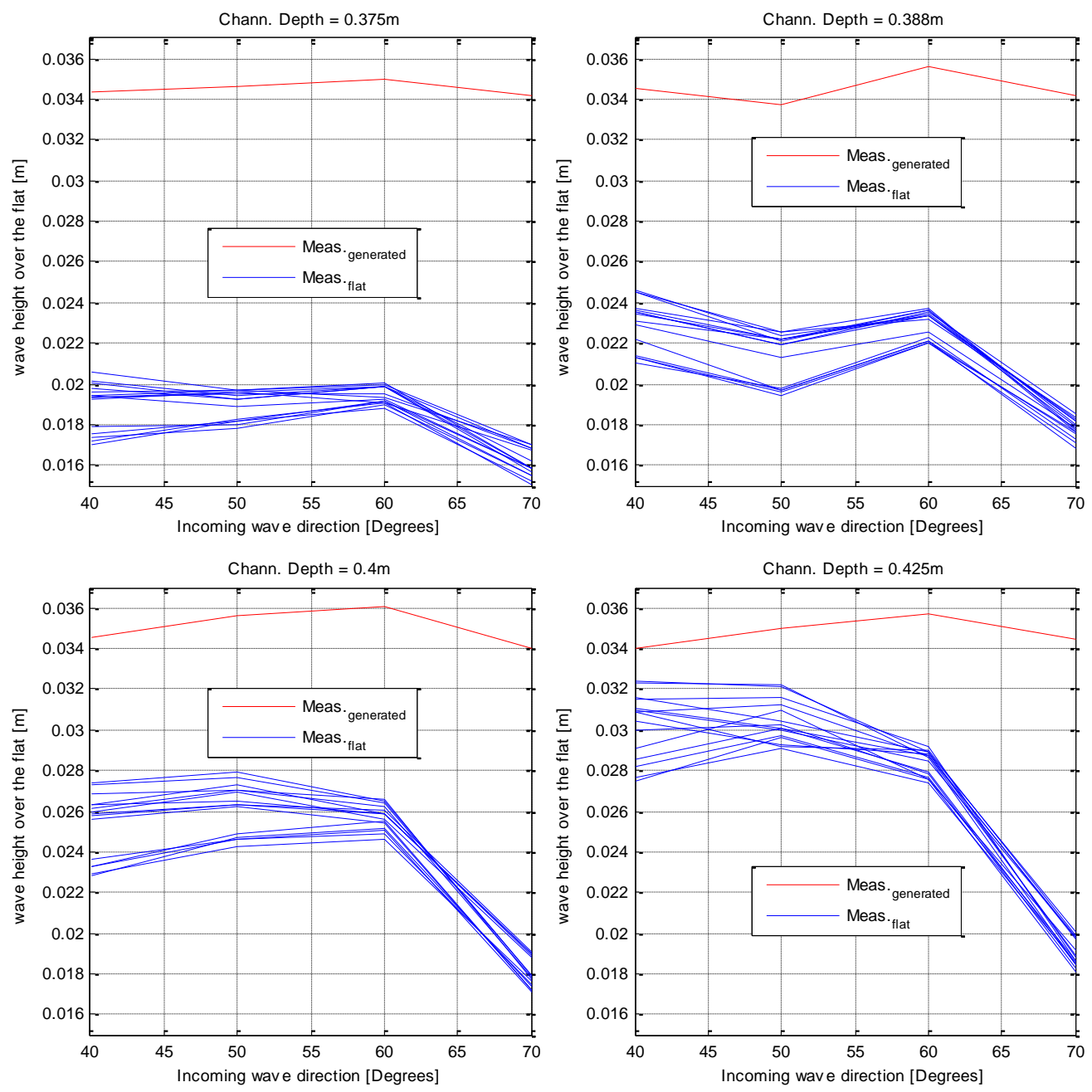

Figure 17, Wave height over the flat from the experiment for all measurement locations as a function of the incoming wave direction and the water level

The above analysis did not explain the observed trend, but has resulted in new hypotheses. In the existing refraction formulations, reflection from the slope is not present. If reflection from steep slopes under large approach angles influences the refraction process, it can potentially explain the wave penetration issue in the eastern Wadden Sea area through the tidal inlet. If part of energy, while refraction over steep slopes reflects back in the channel, then wave energy may remain within the channel and propagates through the estuary. Yet, it is not known how it could possibly explain the observed trend of the experiments in the wave direction. The effect of reflection has not been a subject of this study, and could be a subject for future research.

The main conclusion, that summarizes the discussion is that we have not found one physical effect that explains the complete trend in the differences in wave direction over the flat between SWAN and the experiment. 


\section{REFERENCES}

Alkyon (2008). SWAN hindcast in the Eastern Wadden Sea and Eems-Dollard estuary during the Storm of 9 November 2007. Alkyon Report A2191. Authors: J. Adema, G.Ph. van Vledder and O.R. Koop.

Alkyon (2009). Analysis of wave penetration into the Eastern Wadden Sea. Alkyon Report A2302. Authors: G.Ph. van Vledder and O.R. Koop.

Berkhoff, J.C.W. (1972). Computation of combined refraction-diffraction. Proc. 13th Int. Conf. on Coastal Eng., July 1972, Vancouver, Canada. ASCE, New York, N.Y., pp. 471-490.

Booij N. (1983), "A note on the accuracy of Mild-Slope equations", Journal of Coastal engineering (7), pp. 191-203

Booij, N., R.C. Ris and L.H. Holthuijsen (1999). A third generation wave model for coastal regions, Part I, Model description and validation. J. Geophys. Res., 104, C4, 7649-7666.

Borsboom M., N. Doorn, J. Groeneweg and M. van Gent (2000). "A Boussinesq-type wave model that conserves both mass and momentum". Proc. 27th Int. Conf. on Coastal Engineering 148 - 161.

Bouws, E. and G. J. Komen (1983), "On the balance between growth and dissipation in an extreme, depth-limited wind-sea in the southern North Sea", Journal of Physical Oceanography, Vol. 13, 9, pp. $1653-1658$

Deltares (2009a). SBW Wadden Sea, water level modeling. Study on sensitivity of applying spatially varying bed characteristics. Deltares report 1200114-005. Authors: Jan-Joost Schouten and Arne van der Hout.

Deltares (2009b). Penetration of North Sea waves into the Wadden Sea - phase 3: fallback options. Deltares report 1200114-002. Authors: A.R. van Dongeren, A.J. van der Westhuysen, G.Ph. van Vledder and I. Wenneker.

Deltares/Alkyon (2009). Wave propagation through tidal inlet systems. Deltares and Alkyon report 1200114-002-HYE-0006. Authors: A.J. van der Westhuysen, B. Huisman, F. Enet. O. Koop and G.Ph. van Vledder.

Deltares (2010a), "SWAN verification of refraction over steep slope and a tidal flat; a laboratory study", Deltares Report 1202119-004-HYE-0009, Authors: Sepehr Eslami Arab, Ap van Dongeren, Peter Wellens

Deltares 2010b. Synthesis of SBW Belastingen. Deltares report 1202120-006, December 2010

Deltares 2011a. Improvements in spectral wave modeling in complex tidal inlet seas, overview of results of SBW-Waddenzee project 2006-2010. Deltares report 122110-006, may 2011. Authors: Andre van der Westhuysen, Ap van Dongeren, Joana van Nieuwkoop, Jacco Groeneweg, Sepehr Eslami Arab

Deltares (2011a). Improvements in spectral wave modelling in a complex tidal inlet seas. Overview of results of the SBW-Waddenzee project 2006-2010. Deltares report 1202119-006, May 2011.

Hasselmann, K., T. P. Barnett, E. Bouws, H. Carlson, D. E. Cartwright, K. Enke, J. A. Ewing, H. Gienapp, D. E. Hasselmann, P. Kruseman, A. Meerburg, O. Müller, D. J. Olbers, K.Richter, W. Sell, and H. Walden (1973). "Measurement of windwave growth and swell decay during the Joint North Sea Wave Project (JONSWAP)". Dtsch. Hydrogr. Z. Suppl. 12(A8)

Hedges, T.S. 1976. "An empirical modification to linear wave theory", Proc. Inst. Civil Eng., Part 2, Vol. 61, p. 575-579

Kirby, J.T., and Dalrymple, R.A. (1984). "Verification of parabolic equation for propagation of weakly-non-linear waves", Journal of Coastal Engineering 8(3), pp. 219-232

Kuik A.J., van Vledder G. Ph. 1988, "A method for the routine analysis of pitch-and-roll buoy wave data", J. of Physical Oceanography Vol. 18, PP. 1020-1034.

Lygre, A. and H.E. Krogstad (1986). "Maximum entropy estimation of the directional distribution in ocean wave spectra". J. Phys. Oceanogr., Vol. 16, pp. 2052-2060

Panicker N. N. and L. E. Borgman 1971, "Directional Spectra from wave gauge arrays", Proceedings of 12th International Conference on Coastal Engineering, Taipei, vol. 1,B. L. Edge, ed ASCE, Newyork, chap 50, pp. 660-674

van der westhuysen et al 2012, Van der Westhuysen, A.J., A.R. van Dongeren, J. Groeneweg, G.Ph. van Vledder, H. Peters, C. Gautier, J.C.C. van Nieuwkoop (2012). Improvements in spectral wave modeling in tidal inlet seas. Journal of Geophysical Research, Vol. 117, C00J28, doi:10.1029/2011JC007837

Van Vledder, G.Ph., M. Zijlema and L.H. Holthuijsen (2010). Revisiting the JONSWAP Bottom Friction Formulation in Wind-Driven Storm Seas. Proceedings Of The International Conference On Coastal Engineering, 1(32). 